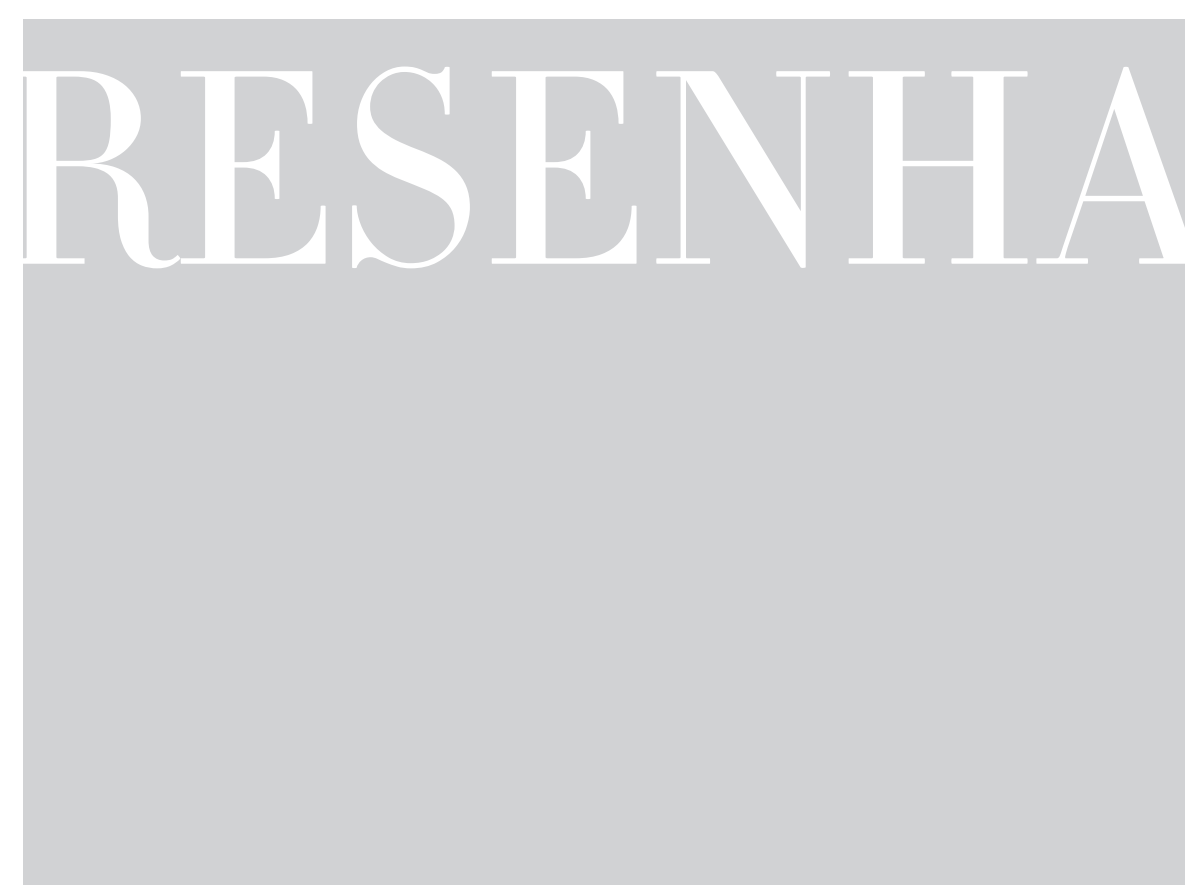

TEORIAS DE CURRÍCULO

ALICE CASIMIRO LOPES, ELIZABETH MACEDO

SÃO PAULO: CORTEZ, 2011. 280 p.

Apresento, neste texto, uma resenha do livro Teorias de currículo, de autoria de Alice Casimiro Lopes e Elizabeth Macedo, uma publicação marcante, com notável distinção e elegância. Com efeito, o campo do currículo no Brasil é contemplado com a divulgação de mais uma obra específica, levada a efeito pela editora Cortez, vindo suprir uma lacuna nos cursos de pedagogia e licenciaturas e até nos cursos de pós-graduação em educação.

A ousadia de publicar um livro denominado Teorias de currículo é reconhecida pelas próprias autoras, pela complexidade temática, geradora de questionamentos, circunstanciada pelos riscos de inclusões e exclusões próprias ao desafio de apresentarem um texto com essa envergadura. Ao elencarem as motivações para a elaboração da obra, Lopes e Macedo afirmam que a escrita sinóptica cerca-se de muitos riscos, sobretudo porque, entre outras alusões, os "perigos são intensificados numa contemporaneidade em que a ideia de fundamento é posta em xeque" (p. 9). Todavia, a ausência de produções textuais com essa abordagem torna justa a suposta audácia de sua escritura, constituindo-se numa salutar intrepidez, num ato corajoso para tornar possível sua edição.

As autoras iniciam o livro situando os muitos perigos que circundam a sua produção, e enfrentam a provocação sem, no entanto, pretenderem fixar sentidos. Relatam a dificuldade na organização e eleição dos temas, tendo em vista a hibridização do campo curricular, 
com enfoques e perspectivas múltiplas. Abordam proposições teóricas, lançam ideias, ampliam a possibilidade de comunicação do campo, referenciam significados, sem, entanto, se distanciarem dos textos originais.

Trata-se de um texto que tem relação com o aspecto autobiográfico que expressa. Abrange uma discussão intensa, com redação e linguagens acessíveis, abordando, com rigor, premissas substancialmente importantes para os estudos do campo curricular. O livro é composto por onze capítulos, cuja abordagem temática focaliza contextos espaço-temporais diversos, ao mesmo tempo em que dialoga com tendências, perspectivas, epistemologias, deslocamentos e desconstruções, fazendo emergir percursos de autoria na consecução dos processos investigativos vivenciados pelas autoras.

No primeiro capítulo, nomeado "Currículo", as autoras antecipam o posicionamento acerca da impossibilidade de responder à pergunta “O que é currículo?”, uma vez que a escrita e definição de um termo traz embutido o conjunto de perspectivas e conotações em que a acepção está inserida. Preferem considerar que o movimento de criação de novos sentidos para o termo currículo remete a sentidos prévios, ainda que para negá-los ou para reconfigurá-los; por isso a opção de atentar para sentidos que têm se tornado mais salientes no decorrer da existência dos estudos do campo.

Nesse capítulo, as autoras historicizam a trajetória dos estudos curriculares, referenciando autores e fundamentos que se tornaram relevantes na historiografia desses estudos. Situam origens e abordagens que foram acompanhando o desenvolvimento do campo; retratam discussões levadas a efeito pela influência dos movimentos do início da industrialização americana e, nos anos 1920, no Brasil, com o movimento da Escola Nova, em que a tônica da decisão sobre "o que ensinar" ganha fôlego, o que leva muitos autores a associarem o início dos estudos curriculares a esse período.

O capítulo dois, denominado "Planejamento", aborda o tema mais recorrente para a noção de currículo da tradição, que o concebia como o estudo das formas de planejá-lo. Essa noção de planejamento ainda é bastante forte no meio educacional brasileiro, compreensão que se estende também sobre o currículo. Para apresentar historicamente o tema, as autoras focalizam a racionalidade tyleriana, cuja influência no Brasil foi marcante, principalmente até meados dos anos 1980, com resquícios tênues, mas muito presentes em reformas educacionais.

As autoras fazem uma retrospectiva da elaboração curricular de Tyler, relacionando-a à abordagem do currículo por competência, utilizada por César Coll, organizador de propostas curriculares de vários países, inclusive do Brasil. Lopes e Macedo não se restringem a relatar os estudos sobre o tema, mas sugerem possibilidades de pensar o planejamento curricular a partir de outras bases teóricas, incorporando 
discussões pós-estruturais. Nessa direção, indicam o movimento desenvolvido por Pinar e, na mesma linha autobiográfica, destacam a ideia de "currículos centrados nas histórias de vida dos sujeitos a partir das quais os 'conteúdos' curriculares se tornam existencialmente significativos" (p. 66). Fazem referência à experiência de planejamento em torno de temas culturais, defendida por Sandra Corazza, em publicações nos anos 1990, que compreende o planejamento como um texto pedagógico produzido nas escolas e o ato de planejar como uma prática deliberada de construção de outros significados curriculares.

O terceiro capítulo é alusivo ao "Conhecimento". De acordo com as autoras, esse talvez seja o tema que congrega maior destaque ao longo da história do currículo. Em torno do questionamento sobre qual conhecimento deve ser ensinado, as discussões acerca do que é currículo ganham força e servem de respaldo para a consecução daquilo que diferentes concepções e interesses colocam em apreço. É, pois, sobre o conhecimento a ser ensinado-aprendido que finalidades da escolarização tomam corpo e se edificam.

O quarto capítulo, “Conhecimento escolar e discurso pedagógico”, é apresentado em três tópicos: transposição didática, recontextualização e principais contribuições da recontextualização e da transposição didática para as teorias de currículo. Lopes e Macedo afirmam que questões curriculares estão diretamente relacionadas com o processo de transformar os saberes legitimados socialmente em matéria escolar; daí porque algumas teorizações se desenvolveram no sentido de procurar entender o processo de pedagogização para fins de ensino e seu impacto na organização do conhecimento.

Finalizando o capítulo, as autoras apresentam as principais contribuições das teorias da transposição didática e da recontextualização para as teorias de currículo, evidenciando-a como uma teoria potente para análise das políticas de currículo, uma vez que há um processo inerente à circulação de discursos e textos geradores de diferentes leituras contextuais, permitindo conceber que a "recontextualização pode se desenvolver pela produção de híbridos culturais” (p. 106).

O título do quinto capítulo é "Disciplina" e trata, entre outros assuntos, da concecução de finalidades educacionais por meio das disciplinas, considerando a organização disciplinar como uma técnica de organização e controle de saberes, sujeitos, espaços e tempos na escola. Salientam que essa organização disciplinar vigora em currículos de diferentes países, configurando uma noção de currículo centrado nas disciplinas. Abordam a teorização de Ivor Goodson, pesquisador da história das disciplinas escolares, para quem a disciplina escolar não é decorrente de uma simplificação de conhecimentos de nível superior para o nível escolar, mas "construída social e politicamente nas instituições escolares, para atender a finalidades sociais da educação” (p. 119). 
As autoras fazem referência aos estudos de Popkewitz, para quem não há um saber a priori, mas lutas políticas que se hegemonizam em campos disciplinares. Lopes e Macedo afirmam que "as disciplinas são construções sociais que atendem a determinadas finalidades da educação e, por isso, reúnem sujeitos em determinados territórios, sustentam e são sustentadas por relações de poder que produzem saberes” (p. 121).

"Integração curricular" é o tema do sexto capítulo. Nele, as autoras relatam que a noção de currículo integrado tem perpassado a história do currículo com denominações diversas, entre elas a de currículo global, interdisciplinar, currículo transversal e metodologia de projetos. Em razão dos princípios utilizados como base de integração, as propostas se pautam em três modalidades: integração pelas competências e habilidades a serem formadas nos alunos; integração de conceitos das disciplinas, mantendo-se a lógica dos saberes disciplinares de referência; abordagem de integração das políticas mais amplas, com respaldo em demandas sociais.

As autoras mencionam os propostos da interdisciplinaridade e destacam os estudos de Veiga-Neto, que defende os projetos pluridisciplinares, aceitando, assim, a legitimidade das disciplinas, quer do ponto de vista epistemológico, quer do ponto de vista contextual, uma vez que assim são organizados os currículos. Na sua visão, através dos tempos, o currículo tanto é um produto quanto é capaz de produzir formas de pensar.

No sétimo capítulo, "Prática e cotidiano" ganham destaque. Esse é mais um tema relevante e as autoras informam que ele acompanha o desenvolvimento da teorização do campo do currículo, assumindo diferentes sentidos. Referem-se a abordagens da teoria do currículo que se têm, historicamente, voltado para a discussão da prática e do cotidiano dos sujeitos, e destacam que o foco de tais pesquisas é a busca pelo entendimento da "epistemologia" da prática.

O oitavo capítulo chama-se "Emancipação e resistência”. As autoras registram que o deslocamento dos estudos curriculares das análises macrocontextuais para a escola passa por dois movimentos: os estudos que elegem a prática e o cotidiano, desnaturalizando a separação entre desenvolvimento e implementação curricular, e outros que se contrapõem às teorias da correspondência e da reprodução. Neste capítulo, dão relevo ao segundo eixo - teoria da resistência -, cujo propósito é “entender a escola como lócus de luta por hegemonia e não como reflexo determinado das relações hegemônicas” (p. 165).

Lopes e Macedo destacam os principais estudiosos da resistência, salientando que a divulgação dessa perspectiva no Brasil é influenciada pela literatura inglesa, haja vista a sua maior influência nas obras publicadas no Brasil. Enfatizam aspectos significativos da teoria da resistência e salientam o deslocamento de trabalhos de determinados teóricos, 
principalmente os de Henry Giroux, para a temática da emancipação, como um avanço significativo em relação aos estudos curriculares. Entre os estudos brasileiros sobre emancipação, destacam-se as pesquisas de Inês Barbosa de Oliveira, que trabalha com alternativas curriculares emancipatórias, a partir dos estudos com o cotidiano.

As autoras revelam propósitos de ressignificação da resistência e da emancipação a partir da incorporação dos aportes teóricos pós-coloniais e da teoria do discurso de Laclau e Mouffe, inclusive em seus próprios trabalhos. Defendem que há múltiplas demandas particulares de projetos emancipatórios em busca de hegemonização, em contextos diversos, "uma proposta contingencialmente construída, em lutas culturais e políticas” (p. 183).

No nono capítulo, "Cultura” dá título ao texto. Em consequência da multiplicidade de sentidos que o conceito congrega na teoria curricular, as autoras anunciam que a abordagem dessa temática não é uma tarefa simples. Salientam que, tradicionalmente, nas perspectivas funcionalistas, a principal função da escola seria a socialização dos sujeitos, levando-os a partilhar uma mesma cultura, mas, contemporaneamente, “essa cultura, de caráter universal, é posta em questão por sociedades que se mostram, a cada dia, mais multiculturais" (p. 185).

As autoras ressaltam as contribuições teóricas de Stuart Hall e Henry Giroux, situando a importância do contato do campo do currículo no Brasil com os estudos culturais, ocorrido durante a segunda metade dos anos de 1990. Citam um texto emblemático para os estudos curriculares, de autoria de Stuart Hall, denominado A centralidade da cultura: notas sobre as revoluções culturais de nosso tempo, publicado em 1997. A partir de Stuart Hall, surge o entendimento de que assumir a perspectiva pós-estrutural significa "aceitar que todo e qualquer sentido somente pode ser criado dentro de sistemas de linguagem ou de significação” (p. 202).

Lopes e Macedo reconhecem a importância dos trabalhos de Tomaz Tadeu da Silva, no Brasil, em seus diálogos com Foucault, Derrida, Deleuze, Gatarri. Destacam autores como Nestor Canclini e Home Bhabha, que são referências importantes nos estudos mais recentes do campo do currículo no Brasil, "exemplos de diferentes formas como a cultura como processo híbrido de representação pode ser apropriada” (p. 208).

O décimo capítulo trata de "Identidade e diferença". As autoras anunciam que, ao tratarem dessa temática, estão atentas em considerar "aspectos das identidades que se relacionam com a participação dos atores sociais em determinados grupos” (p. 216). Para isso, abordam questões que interrogam os mecanismos sociais discursivos de estabilização das identidades. Argumentam sobre a importância de pensar a diferença cultural para além da identidade. 
Autores como Stuart Hall, William Pinar, Homi Bhabha, Ernesto Laclau e Chantal Mouffe referenciam os estudos das autoras do texto. Com base em tais fundamentos, salientam a fluidez das identificações e o entendimento dos sujeitos descentrados e políticos. As autoras propõem, por fim, um currículo instituinte, no sentido de desconstruir discursos, desconstruir hegemonias.

O último capítulo do livro é dedicado à "Política”. Nele, expressam-se discussões sobre a separação entre projeto e implementação curricular, as políticas de currículo e o foco na estrutura econômica, a abordagem do ciclo de políticas e, para além desta, os discursos na política de currículo. As autoras sistematizam a escrita do texto apresentando algumas das principais concepções de política a partir de estudos que abordam diferentes perspectivas e teorizações, como a administrativa, a ciência social, os estudos estruturais e pós-estruturais. Assinalam que, tanto no Brasil quanto no exterior, grande parte das análises curriculares é mais voltada à crítica de documentos e projetos do que às investigações relacionadas com as políticas de currículo.

As autoras destacam as contribuições dos estudos de Ball para análise de políticas de currículo, mas aprofundam a discussão, incorporando a teoria do discurso de Ernesto Laclau. Entendem que "qualquer discurso é uma tentativa de dominar o campo da discursividade, fixar o fluxo das diferenças e construir um centro provisório e contingente de significação" (p. 252). Concluem, afirmando que o currículo é uma luta política por sua própria significação e que a divulgação da obra é também uma forma de participar dessa luta.

A partir da leitura de Teorias de currículo, é possível afirmar que as discussões apresentadas, os autores citados, os textos referenciados constituem um arcabouço teórico para estudos interpretativos do campo curricular, potencializando novos estudos, novos sentidos para essa área. Uma leitura indispensável para os que se dedicam à disciplina Currículo em cursos de formação de professores, aos pesquisadores do campo, aos estudantes das licenciaturas e professores de modo geral. O texto é instigante e as contribuições dos estudos evidenciados dão margens a novas interpretações, podendo gerar outros movimentos, outros sentidos, novos significados.

\section{IDELSUITE DE SOUSA LIMA}

Professora adjunta da Unidade Acadêmica de Educação do Campo, do Centro de Desenvolvimento Sustentável do Semiárido da Universidade Federal de Campina Grande - UFCG (PB)

idel.lima@uol.com.br 